\title{
Development of the Use of Unmanned Aerial Vehicles (UAVs) in Emergency Rescue in China
}

Tao Li

Haitao Hu

School of Law, Hebei University of Economics and Business, Shijiazhuang, Hebei, People's Republic of China
Correspondence: Tao $\mathrm{Li}$

School of Law, Hebei University of Economics and Business, Xuefu Road No. 47, Shijiazhuang, 05006I, People's Republic of China

Email litao@heuet.edu.cn

\begin{abstract}
With the frequent occurrence of various disaster events, China has attached high importance to emergency rescue in recent years. Unmanned aerial vehicles (UAVs) are becoming more extensively used in emergency rescue, thanks to their flexibility, intellectuality, and safety in operation. It is therefore timely to evaluate UAV utilization in emergency rescue and explore the impediments to its further development in China. To date, UAVs have been mainly used for on-site monitoring and commanding, relay of communications, delivery of materials, disaster assessment, and life detection. Aerial emergency rescue is a vital component of the whole emergency rescue system in China. In the future, it is recommended that China take measures to boost UAV technical innovation and professional team development and promote the integrated application of manned aircraft and UAVs.
\end{abstract}

Keywords: disasters, rescue scene, drone, technical innovation

\section{Introduction}

Disasters occur often in China. According to the Ministry of Emergency Management of China, in 2020, 138 million people were affected by various natural disasters, about 100 thousand houses collapsed, 19.96 million hectares of crops and plants were damaged, and the direct economic loss reached 370 billion yuan. ${ }^{1}$ Besides natural disasters, there was also damage caused by public health incidents (eg, the COVID-2019 outbreak) and accidents (eg, the collapse of Xinjia Hotel in Quanzhou City on March 7, 2020 ${ }^{2}$ and the explosion in Tianjin on August 12, 2015). ${ }^{3}$ The frequent occurrence of disasters reveals some weak aspects of China's emergency management system, for example untimely warning of disastrous events and the inapplicability of emergency plans. Improving China's emergency management is an urgent task but will take time to accomplish.

At present, emergency equipment and the emergency industry as whole, which ensure good emergency management, have strong support in China. China's 13th Five Year Plan for the Construction of a National Emergency Response System has included unmanned aerial vehicles (UAVs) into the list of professional equipment for emergency rescue, ${ }^{4}$ indicating that UAVs are likely to be more extensively used in the future. UAVs are endowed with the advantages of simple operation, low cost, multiple functions, flexibility, and speed, and are well suited for on-site rescue. They have been widely used in many other fields, where valuable practical experiences have been accumulated. By applying those experiences to emergency rescue, the rates of morbidity and mortality among people affected by disasters could be improved. Based on a review of the literature, official data, and news reports, this article provides an overview of UAV 
utilization in emergency rescue in China and summarizes the impediments to further development in this regard. The article also puts forward some suggestions on advancing the development of UAV emergency rescue in terms of policy adjustment, technical innovation, and personnel development.

\section{The Development of UAV Production and Utilization in China}

A UAV, also known as a drone, is an aircraft controlled by a remote station or flying automatically without a human pilot on board. In recent years, UAV technology has developed rapidly. Lighter and more "intelligentized" UAVs have been widely used in agricultural production, fire rescue, remote sensing mapping, police work, and entertainment. ${ }^{5}$ At present, civil utilization has occupied only a minor share of China's UAV market. However, the potential for the development of civil UAVs in China is favorable, considering that the UAV industry has been included into the plan of Made in China 2025 and the military-civil fusion strategy has been in progress. ${ }^{6}$

According to China's Civil UAV Development Report, in 2019, China's civil UAV market was worth 21 billion yuan. UAVs for industrial use are subject to increasing demand, accounting for $54.3 \%$ of the civil UAV industry in 2019. ${ }^{7}$ UAV producers are mainly located in southern and eastern China. A UAV industrial cluster has been formed in the Pearl River Delta, with Shenzhen as the core. It is reported that DJI Innovation, a UAV producer headquartered in Shenzhen, has taken the leading position in the UAV industry, accounting for nearly $70 \%$ of the global market. ${ }^{8}$

UAVs have been put into use in various fields in China with positive results. On behalf of the traffic police authorities in Beijing and Shanghai, UAVs perform an aerial patrol function to monitor traffic flow and traffic violations. In agriculture, UAVs have become a growing force, not only for sowing and pesticide spraying but also for monitoring diseases and pests, thus greatly improving the efficiency of agricultural operations. UAVs also make a great contribution to reducing the risks of operations high above the ground, for instance, clearing the walls high-rise buildings and extinguishing fire therein. Further, UAVs play an important role in remote sensing surveying and mapping, police security, public entertainment, and other fields.

\section{Overview of UAV Utilization in Emergency Rescue}

The application of UAVs in emergency rescue relies mainly on remote sensing technology. UAV flight control includes ground control and airborne control. Through wireless communication, ground control sends commands to a UAV's flight and collects relevant data for further processing, modeling, and analysis. Satellite remote sensing and manned aerial remote sensing are restricted in the acquisition of rescue information because of the nature of the rescue environment, cost, and other factors. UAVs' remote sensing system, with better spatial-temporal resolution and real-time performance, is useful in rescue situations. ${ }^{9}$ In addition, a UAV can carry a variety of facilities and equipment, including high-definition cameras, thermal imagers, infrared night vision equipment, and emergency communications equipment. These facilities can be used according to the needs of the situation and can take clear pictures and transmit data more efficiently, thus improving the efficacy of rescue.

Some other countries have also incorporated UAVs into their emergency rescue systems. Early in 2005, the United States used UAVs for search and rescue in the aftermath of Hurricane Katrina. ${ }^{10}$ In 2011, Japan used a UAV equipped with sensors to check the range of nuclear radiation of the Fukushima power plant after it was damaged by an earthquake. ${ }^{11}$ UAVs were first utilized in China after the 2008 Sichuan earthquake. In the early days after the earthquake, people had no access to information about the disaster, because all communications links to the affected areas were destroyed. Then, relevant authorities sent professionals to capture images of the scene by utilizing UAVs' remote sensing (aerial photography) function, allowing experts and commanders to study the disaster and make decisions. ${ }^{12}$

To date, UAVs have been an important force in emergency rescue in China. For instance, DJI Innovation formed an emergency rescue league to promote UAV use in this field. As of September 2020, this company had participated in more than 200 rescue cases nationwide. ${ }^{13}$ During the 2020 pandemic period, a total of 780 UAVs from 99 UAV enterprises took part in tasks for pandemic prevention and control, accounting for $85 \%$ of all the aircraft in epidemic rescue. ${ }^{14}$

\section{Specific UAV Utilization in Emergency Rescue in China}

\section{Scene Monitoring}

An important role UAVs can play in emergency rescue is monitoring the scene and assisting command and dispatch. The circumstances of disaster events often change rapidly, with a high possibility of secondary disaster. For instance, in the 2015 Tianjin explosions, fires caused by the initial explosions continued to burn uncontrolled, resulting in 
additional blasts. The 2008 Sichuan earthquake and numerous aftershocks caused debris flow, landslide, and other disasters. These incidents highlight the importance of instantly acquiring information about the disaster scene to enable rescue action at the most critical times. UAVs have the advantage of being less restricted than other aircraft by terrain, night-time darkness, and other environmental conditions.

UAVs carrying zoom HD camera equipment can reflect the details of the scene through multidimensional photography by adjusting hovering height and shooting angles. They can also carry out emergency surveying and mapping of the site and send back that information to those coordinating the rescue. It is reported that a type of UAV produced by DJI Innovation can send back data from 10 kilometers away. ${ }^{15}$ Having acquired comprehensive and accurate information about the situation, the decisionmaker can then direct the dispatch of rescue forces and organize the timely evacuation of people in the vicinity.

UAVs can also carry low-light-level night-vision devices or thermal imagers to observe at night or carry gas detectors to identify an area of toxic gas leakage. As there are other potential risks at the disaster scene, several UAVs can be used in succession to monitor the scene, so that the commander can adjust the rescue plan in real time. For instance, at the scene of a forest fire, a UAV carrying thermal imagers can continuously monitor the situation and provide fire crews with information about the boundary and spread of the fire and the paths for entry and retreat.

\section{Communications Relay}

Efficient and reliable communication is the key to search and rescue in the case of disaster. UAVs can act as temporary means of relaying communications when the base station in the disaster area is no longer running. ${ }^{16}$ Meanwhile, large and medium UAVs can also directly participate in the rescue. For example, at the scene of a forest fire, an earthquake, or other disaster, the communications network is often destroyed and difficult to restore quickly. In this case, a long-endurance UAV can be used to establish wireless communication links by carrying communications equipment on board, restoring the ability to exchange information. When the conditions in the disaster area permit, a stable and temporary communications base station can also be established with a tethered UAV.

UAVs can also perform high-altitude lighting during a night-time search and rescue operation when natural light sources are not available. A case in point was the search and rescue following the collapse of the Fujian Xinjia Hotel one evening in March 2020, when a tethered UAV unrestricted in endurance was utilized for high lighting, thus ensuring continuity of the rescue operation. ${ }^{17}$ Similarly, during the early days of the coronavirus outbreak in Wuhan, the night-lighting function of UAVs was helpful in enabling the extremely rapid construction of Huoshenshan Hospital and Leishenshan Hospital, designed to accept exclusively coronavirus patients. $^{18}$

\section{Materials Delivery and Disaster Assessment}

The delivery of materials and tools is an essential part of emergency rescue, and UAVs can fulfill these tasks quickly and accurately. In the event that materials and rescue equipment cannot be delivered owing to paralyzed ground traffic, air transportation is the most efficient and effective alternative. Large and medium-sized UAVs with relatively larger load capacities can drop lifebuoys for drowning people. UAV controllers on the ground can monitor their flight and set their routes, thereby transporting clothing and food to trapped people, delivering medical supplies to those in urgent need and providing rescue workers with a defibrillator and other rescue equipment. At present, a large number of emergency rescue drills include a program of UAV fixed-point delivery. In 2018, a civil-military joint drill was conducted in Beijing, in which the use of UAVs to supply materials was accomplished through cooperation between the air force and civil UAV enterprises. ${ }^{19}$ Many other emergency drills also show that UAV delivery plays an important role in meeting the demands of disaster areas.

Meanwhile, the mapping of disaster areas, being an important part of post-disaster recovery work, needs support from the air. UAVs can finish the on-site mapping for post-disaster assessment conveniently, thanks to their low susceptibility to geographical conditions. The orthographs taken by a UAV can also be converted to $3 \mathrm{D}$ modeling images. For large disaster areas, technicians can also capture multiple groups of images to realize 3D modeling, so as to delineate the affected area and provide the basis for subsequent recovery work.

\section{Life Detection}

Finding signs of life and rescuing victims in time are the primary goals of rescue work. The life detector is an 
effective tool for searching for life at disaster scenes. Traditionally, life detectors are carried by rescue staff personally, which may be burdensome and risky. In contrast, UAVs equipped with life detectors perform this task rapidly and with security guarantees for rescue staff. Specifically, multi-rotor UAVs are ideal in this regard, since they are more controllable and have no special requirement for taking-off and landing sites. Research shows that multi-rotor UAVs can carry infrared detectors and radar detectors. Infrared detectors search for life by perceiving the specific infrared band emitted by human bodies ${ }^{20}$ while radar detectors can analyze life signs using the Doppler effect. ${ }^{21}$ It is suggested that UAVs evaluate breathing status more correctly when they land on victims' bodies than when hovering over them. ${ }^{22}$ Also, cardiopulmonary motion detection on the body surface may be a new technique for remote life sensing assessment of survivors in the future. ${ }^{23}$ Except for some emergency drills, cases of rescue by UAVs equipped with life detectors have not been reported in China, but UAV-assisted life detection is expected to be more widely used in the future.

\section{Challenges for UAV Utilization in Emergency Rescue in China}

Despite the advantages mentioned above, UAVs are not yet comprehensively utilized in China. Monitoring, early warning, command, and dispatch are the key aspects of air rescue, requiring systemic support from equipment, staff, infrastructure, and the responding system. However, UAV emergency rescue as a part of air rescue is still in its infancy stage in the country.

\section{Deficient Emergency Responding System}

Experience during the COVID-19 pandemic shows that there is still room for improvement in China's air emergency rescue system. No systemic responding mechanism exists to enable a UAV to participate in emergency rescue. Moreover, there is no unified high-level coordination and dispatch of UAVs, and their participation in rescue work depends basically on the voluntariness of UAV producers themselves. A normalized mechanism for UAVs' participation in emergency rescue has yet to be established, as can be further demonstrated from the following.

First, there is no clear legislative support for utilizing UAVs in emergency rescue. Relevant laws provide only a highly generalized description (see Table 1), without specific rules concerning the legal status of UAV rescue bodies and the standards of UAV rescue operation. UAV emergency rescue involves links with public security, meteorology, transportation, and other fields, but existing laws are also unclear in this regard.

Second, there is strict control over low-altitude airspace in China, flights in this airspace being generally restricted or prohibited, and the opening process is slow. Low-altitude airspace is the main airspace for UAVs to participate in emergency rescue. ${ }^{24}$ Although an application for flights in low-altitude airspace can be submitted to the relevant authorities, the review process is prolonged and incompatible with the flexibility that the use of UAVs requires. Thus, the development of UAVs in emergency rescue has been hindered.

Last, China's Emergency Response Law lays down a principle of unified leadership and hierarchical responsibility. However, the air emergency rescue force can come

Table I Laws and Regulations Concerning Aerial Rescue in China

\begin{tabular}{|c|c|}
\hline Title of Legislation & Relevant Articles \\
\hline $\begin{array}{l}\text { Civil Aviation Law (came into force March I, 1996; } \\
\text { amended December 29, 2018) }\end{array}$ & $\begin{array}{l}\text { Article 148: An enterprise engaged in general aviation services for profit shall conclude } \\
\text { a written contract with its users, except for flights for rescue or disaster relief in } \\
\text { emergency situations. }\end{array}$ \\
\hline $\begin{array}{l}\text { Regulations on Civil Aviation Emergency Management } \\
\text { (came into force April 17, 2016) }\end{array}$ & $\begin{array}{l}\text { Article 22: Civil aviation authorities shall cooperate with relevant government } \\
\text { departments, enterprises, and institutions to establish a system of working in which civil } \\
\text { aviation authorities can assist and collaborate with national and local governments and } \\
\text { relevant departments in emergency response. }\end{array}$ \\
\hline $\begin{array}{l}\text { National Overall Emergency Plan for Public } \\
\text { Emergencies (came into force January 8, 2006) }\end{array}$ & $\begin{array}{l}\text { Article } 1.5(6) \text { : In order to improve the abilities to deal with public emergencies, } \\
\text { scientific research and technological development in public security shall be } \\
\text { strengthened, advanced technologies and facilities for monitoring, forecasting, preventing } \\
\text { and responding to emergency events shall be adopted, and experts and professionals shall } \\
\text { be given full scope to act. }\end{array}$ \\
\hline
\end{tabular}


from the army, airlines, government, and general aviation enterprises, but currently there is no systemic mechanism for collaboration among these institutions. Administrative control over UAVs is unclear, being divided among multiple authorities that have no sharing of information. Owing to the complexity of applying for airspace, crucial rescue opportunities are likely to be missed and rescue efficiency reduced.

\section{Incompetent Technical Support}

Although the UAV industry has developed rapidly in recent years and UAVs can be utilized on various occasions, there are still technical deficiencies in support. One is the issue of endurance. At present, most UAVs are equipped with low-power batteries. Even the newly developed UAVs that fly up to 4.5 hours with the help of hydrogen fuel cells cannot fully meet the time requirement of a round-the-clock rescue operation. ${ }^{25}$ Additionally, the safety of UAVs themselves cannot be ignored. UAVs usually fly at low altitudes, and their automatic obstacle avoidance function is imperfect; thus, they are likely to collide with other objects, especially in densely populated areas, resulting in secondary harm. Moreover, the environment around disaster areas is often subject to unfavorable conditions, such as strong wind, high temperature, low temperature, or high altitude, which may curtail the ability of UAVs to fly.

\section{Inadequate Professional Rescue Staff}

As high-technology products, UAVs need professional personnel to undertake their operation and maintenance, especially when performing emergency rescue tasks. Currently, there is no well-established system for training UAV professionals in China. Many UAV flyers or operators come into this career via hobby flying. Although some may be highly skilled, they have not received formal training to obtain a license, leading to such problems as nonstandard operation and incompetence for complex tasks. According to the statistics of the Civil Aviation Administration of China (CAAC), as of the end of 2019, there were more than 60,000 holders of UAV licenses. The Ministry of Human Resources and Social Security of China predicts that the number of people wishing to register as UAV flyers could reach one million in the next five years. This means that the current capacity of UAV license holders is far from meeting the demand for UAV flyers, which also demonstrates the lack of professional UAV rescue workers. To date, most cases of UAV participation in rescue work have occurred following communication between the CAAC and major UAV associations, and there is no company specialized in aerial emergency rescue. In addition, there are different administrative structures and varying degrees of equipment availability in different places. Even when a person holds a UAV license, he or she still cannot proceed with rescue work owing to a lack of practical experience.

\section{Suggestions for Promoting UAV Utilization in Emergency Rescue in China}

In order to further promote the development of UAV emergency rescue in China, we put forward the following suggestions.

\section{Improving the Aerial Emergency Rescue Management System}

As a major facet of a nation's emergency rescue system, aerial emergency rescue needs well-designed laws and regulations to guide its development. In China, flight applications, route planning, and other airspace matters are currently governed by fragmented and overlapping authorities, including the State Council, the Military Commission of the CPC Central Commission, the CAAC, and the Ministry of Public Security. Such a multiple management system cannot meet the demand for UAVs to conduct rescue flights promptly and flexibly. The system therefore needs to be simplified. The following are ways in which this could be done.

First, China should have more specific laws and regulations regarding UAVs' participation in emergency rescue and promote the standardization of UAV rescue through the formulation of technical specifications and rescue evaluation mechanisms. Second, there should be a clear separation of powers among the army, the government, civil aviation enterprises, and general aviation enterprises regarding airspace management. A specific government department should be designated to be responsible for the unified organization and coordination of air emergency rescue. The low-altitude airspace should be further opened, and the airspace application procedures should be simplified, so that relevant enterprises can be motivated to participate in emergency rescue in a more flexible way. Finally, considering that a well-prepared emergency rescue system demands more capable UAVs, UAV production should be standardized to ensure their 
safety when performing aerial rescue tasks. Establishing an aerial emergency rescue system conducive to conducting quick, efficient, and unified rescue operation is essential if UAVs are to play a more significant rule in public security service.

\section{Promoting UAV Technical Innovation}

Flight endurance is the key issue in UAV research and development. Most UAVs are powered by batteries that cannot provide sufficient power support. In order to perform round-the-clock monitoring in emergency rescue, UAVs' flight endurance must be boosted by highperformance batteries. Additionally, it is necessary to increase their endurance in a severe environment such as strong wind or extreme highs and lows of temperature. UAVs can also be made more intelligent by utilizing artificial intelligence, 5G technology, and satellite positioning, so that they can have environment perception, avoid obstacles, and even return automatically when encountering high-risk conditions. The technical advance from remote-controlled UAV to fully autonomous UAV will be another breakthrough that is likely to happen in the near future. Furthermore, an integrated communication platform created by connecting the UAV network to a cellular network or $5 \mathrm{G}$ network may facilitate multidirectional communication among UAVs, ground rescue teams, and other rescue units.

\section{Enhancing Professional Training and Staff Development}

The high requirements of UAV rescue work demand highlevel professionals, who need to be trained and organized into professional UAV rescue teams. Establishing such teams should be the task of local governments in China, along with ensuring the availability of UAV rescue equipment and other infrastructure. Currently, professional UAV rescue teams have been set up in only a few regions, such as the UAV team of the Sichuan Mountaineering Association Rescue Team and the UAV Emergency Support Team incorporated by the Guangxi UAV Technology Application Association. ${ }^{26}$ In July 2020, Chongqing Municipal Government formed an aerial emergency rescue team stationed in many UAV bases, which can serve nearly all the municipal regions. ${ }^{27}$ Meanwhile, UAV producers should contribute more toward the UAV emergency rescue cause by increasing collaboration with the government. The community of UAV volunteers should be enlarged and encouraged to cooperate more closely with professional UAV rescue teams, so as to form a regular UAV rescue force with a strong sense of public responsibility. Additionally, police air forces can also join in rescue tasks. As of June 2021, there were 39 police air teams in China with professional UAV operators, enabling UAVs to be put into use in emergency rescue. $^{28}$

\section{Furthering Joint Operation Between UAVs and Manned Aircraft}

Manned aircraft are currently still unquestionably the major force in aerial emergency rescue all around the world. Compared with UAVs, rescue helicopters have rich rescue experience and a larger capacity to transport materials, equipment, and wounded persons, even in a difficult rescue environment or at sea. However, rescue helicopters carry a high consumption cost and must comply with strict conditions for take-off and landing. In contrast, UAVs have high autonomy, low cost, flexible operation, lax take-off and landing requirements, and of course no personal safety risks. Thus, promoting the combined utilization of UAVs and manned aircraft gives full merit to their respective strengths. For instance, in order to reduce personnel and property losses caused by unfamiliarity with a rescue scene, a UAV can first fly there to send back images, which are then used as the basis for deploying ground rescue or manned aircraft rescue.

\section{Conclusion}

In step with the development of UAV technology, UAVs are beginning to show their skills in emergency rescue. Currently, UAV utilization in emergency rescue is mainly evident in three aspects, namely real-time monitoring, post-disaster search and rescue, and post-disaster assessment. Rescue activities are in urgent need of information and logistics, and UAVs are capable of such tasks as mapping, command and dispatch, delivery of goods, and life detection. Further research and development in UAV technologies and adaptation of relevant regulations will permit UAVs to have more extensive application in emergency rescue in China.

\section{Funding}

This work was supported by Hebei Education Department [Grant ID: Science and Technology Project \#SY202118]. 


\section{Disclosure}

The authors report no conflicts of interest in this work.

\section{References}

1. Ministry of Emergency Management of China. Statistics on natural disasters in April 2021; 2021. Available from: http://www.gov.cn/ xinwen/2021-01/12/content_5579258.htm. Accessed May 4, 2021.

2. CNN. China quarantine hotel collapse left 29 people dead; 2020. Available from: (195) China quarantine hotel collapse left 29 people dead (cnn.com). Accessed May 4, 2021.

3. Yahoo. Huge blasts at Chinese port kill 50, injure more than 700; 2015. Available from: Huge blasts at Chinese port kill 50, injure more than 700 (yahoo.com). Accessed May 4, 2021.

4. Central People's Government of China. The 13th five year plan for the construction of a national emergency response system; 2017. Available from: http://www.gov.cn/zhengce/content/2017-07/19/con tent_5211752.htm. Accessed May 4, 2021.

5. Valavanis KP, Vachtsevanos GJ. UAV applications: introduction. In: Valavanis K, Vachtsevanos G, editors. Handbook of Unmanned Aerial Vehicles. Dordrecht: Springer; 2015.

6. Central People's Government of China. Interpretation of "made in China 2025": promoting the development of aviation equipment; 2016. Available from: http://www.gov.cn/zhuanti/2016-05/12/con tent_5072767.htm. Accessed May 4, 2021.

7. China Air Transport Association. China Civil UAV development report; 2020. Available from: http://rcussd.nwpu.edu.cn/info/1095/ 1813.htm. Accessed May 4, 2021.

8. Chin KSH, Ying SYK, Zhang Y, Siu ACY. Da Jiang Innovation, DJI: the future of possible. Acad Asian Bus Rev. 2017;3(2):83-109. doi:10.26816/aabr.3.2.201712.83

9. Li XY, Han ZH, Xie HY. Application of UAV aerial remote sensing system in disaster emergency rescue. Technol Market. 2020;27 (3):126-128.

10. University of South Florida. USF deploys unmanned aerial vehicles to Katrina rescue operation. ScienceDaily; September 8, 2005. Available from: www.sciencedaily.com/releases/2005/09/ 050908081119.htm. Accessed May 4, 2021.

11. Estrada MAR, Ndoma A. The uses of unmanned aerial vehicles UAV's (or drones) in social logistic: natural disasters response and humanitarian relief aid. Procedia Comput Sci. 2019;149:375-383. doi:10.1016/j.procs.2019.01.151

12. China Central Television Network. A UAV completes aerial photography of earthquake-stricken area and gets images independently; June 30, 2008. Available from: http://news.cctv.com/china/20080630/ 100508.shtml. Accessed May 4, 2021.

13. China Economy. DJI Innovation sponsored an emergency rescue alliance; September 23, 2020. Available from: http://www.ce.cn/ cysc/tech/gd2012/202009/23/t20200923_35803283.shtml. Accessed May 4, 2021.
14. General Aviation Management System. Data analysis on the contribution of general aviation to coronavirus pandemic prevention; March 4, 2020. Available from: http://www.ce.cn/cysc/tech/gd2012/ 202009/23/t20200923_35803283.shtml. Accessed May 4, 2021.

15. IT Family. Mavic Air 2 UAV of DJI Innovation: digital image transmission up to $10 \mathrm{~km}$; April 28, 2020. Available from: https:// www.ithome.com/0/484/847.htm. Accessed May 4, 2021.

16. Johansen TA, Zolich A, Hansen T, Sørensen AJ Unmanned aerial vehicle as communication relay for autonomous underwater vehicle - field tests. IEEE Globecom Workshops; 2014:1469-1474.

17. Tencent. Digitalization of accident scene: UAV assisting emergency rescue of Xinjia Hotel; March, 2020. Available from: https://new.qq. com/rain/a/20200416A0T27N00. Accessed May 4, 2021.

18. Shaoxing Jiusan Society. Help from thousands of miles away: UAV lighting up the construction site of Huoshenshan Hospital and Leishenshan hospital; February 10, 2020. Available from: http:// jsxs.sx.gov.cn/art/2020/2/10/art_1482937_42065546.html. Accessed May 4, 2021.

19. Du X. On the application of UAVs in emergency rescue. China Emerg Rescue. 2018;13(3):51-53.

20. Yang W, Zhou W. Application of multi-rotor UAVs in emergency rescue. Technol Innov Appl. 2020;15:179-180.

21. Li C, Chen F, Jin J, et al. A method for remotely sensing vital signs of human subjects outdoors. Sensors. 2015;15(7):14830-14844. doi: $10.3390 / \mathrm{s} 150714830$

22. Saitoh T, Takahashi Y, Minami H, et al. Real-time breath recognition by movies from a small drone landing on victim's bodies. Sci Rep. 2021;11(1):5042. doi:10.1038/s41598-021-84575-1

23. Al-Naji A, Perera AG, Mohammed SL, Chahl JS. Life signs detector using a drone in disaster zones. Remote Sens. 2019;11(20):2441. doi:10.3390/rs11202441

24. Zhai W, Han B, Li D, Duan J, Cheng C. A low-altitude public air route network for UAV management constructed by global subdivision grids. PLoS One. 2021;16(4):e0249680. doi:10.1371/journal. pone. 0249680

25. Southen.com. A hydrogen-powered UAV flew for 4.5 hours in Shenzhen; April 10, 2016. Available from: http://kb.southen.com/ content/2016-04/10/content_145668323.htm. Accessed May 4, 2021.

26. Zhang F, Tong W, Zhou LD. The application and development of UAV rescue. Chin Med Disaster Relief. 2015;3(11):641-645.

27. People.com. Chongqing built aerial emergency rescue system to promote full coverage of UAV rescue; July 22, 2020. Available from: http://cq.people.com.cn/n2/2020/0722/c365401-34174283. html. Accessed May 4, 2021.

28. Sohu. 39 police air teams have been established; June 12, 2020. Available from: https://www.sohu.com/a/401407286_120214190. Accessed May 4, 2021.
Risk Management and Healthcare Policy is an international, peerreviewed, open access journal focusing on all aspects of public health, policy, and preventative measures to promote good health and improve morbidity and mortality in the population. The journal welcomes submitted papers covering original research, basic science, clinical \& epidemiological studies, reviews and evaluations, guidelines, expert opinion and commentary, case reports and extended reports. The manuscript management system is completely online and includes a very quick and fair peer-review system, which is all easy to use. Visit http://www.dovepress.com/testimonials.php to read real quotes from published authors. 